\title{
Babad Diponegoro dan Asal-Usul Pasarean Gunung Kawi (The Chronicle of Diponegoro and the Origins of the Pasarean Gunung Kawi)
}

\author{
Bani Sudardi ${ }^{\mathrm{a}, 1}$ dan Dwi Sulistyorini, ${ }^{\text {b.2 }}$ \\ anniversitas Sebelas Maret Surakarta, Indonesia \\ ${ }^{\mathrm{b} U n i v e r s i t a s ~ M a l a n g, ~ I n d o n e s i a ~}$ \\ Ibanisudardi@yahoo.co.id; ${ }^{2}$ shoelistr@yahoo.co.id
}

\begin{tabular}{|c|c|}
\hline Article info & A B S T R A C T \\
\hline $\begin{array}{l}\text { Article history: } \\
\text { Received: } 06-12-2020 \\
\text { Revised : } 30-01-2021 \\
\text { Accepted: } 06-02-2021\end{array}$ & $\begin{array}{l}\text { The objective of this paper is to comprehend the process of producing } \\
\text { texts derived from written texts in the form of chronicles and } \\
\text { developing them into oral texts of oral tradition or folklore. The } \\
\text { object of this study is the Chronicle of Diponegoro and the traditions } \\
\text { of Pasarean Gunung Kawi, Malang. The study method is based on } \\
\text { descriptive qualitative research principles. The findings demonstrate } \\
\text { that the Chronicle of Diponegoro does not mention the Pasarean } \\
\text { Gunung Kawi figures directly. Because there are figures from Prince } \\
\text { Diponegoro's war when facing the Company, the text of Prince } \\
\text { Diponegoro serves as a background for the story of Pasarean } \\
\text { Gunung Kawi. The two texts appear to be different, yet the second is } \\
\text { an extension of an existing text. Following the narrative of the } \\
\text { Chronicle of Diponegoro, there is a story about Kyai Zakaria, a } \\
\text { follower of Prince Diponegoro who fled to Malang, East Java. } \\
\text { Furthermore, the text on Pasarean Gunung Kawi was influenced by } \\
\text { community situations, including the relationship between the Malang } \\
\text { people and the Chinese community. }\end{array}$ \\
\hline
\end{tabular}

Keywords:

Babad Diponegoro

Pasarean Gunung Kawi
Indonesian folklore

Tulisan ini bertujuan memahami proses pembuatan teks yang berasal dari teks tertulis berupa babad dan berkembang menjadi teks tradisi lisan atau folklor. Objek kajian ini ialah Babad Diponegoro dan tradisi di sekitar Pasarean Gunung Kawi, Malang. Metode kajian menggunakan prinsip-prinsip penelitian kualitatif deskriptif. Hasil kajian menunjukkan bahwa babad Diponegoro memang tidak secara langsung menceritakan tokoh-tokoh Pasarean Gunung Kawi. Teks Pangeran Diponegoro berkedudukan sebagai latar belakang kisah Pasarean Gunung Kawi karena di dalamnya terdapat tokoh-tokoh dari peristiwa perang Pangeran Diponegoro ketika menghadapi kompeni. Kedua teks tersebut terlihat berlainan, tetapi sesungguhnya teks kedua merupakan suatu pengembangan teks baru dari teks yang sudah ada. Teks Babad Diponegoro dilanjutkan dengan cerita tentang Kyai Zakaria, pengikut Pangeran Diponegoro, yang melarikan diri sampai ke Malang Jawa Timur. Selanjutnya teks tentang Pasarean Gunung Kawi ini berkembang sesuai dengan kondisi yang terjadi di masyarakat, yaitu adanya hubungan antara masyarakat Malang dengan masyarakat China.

Copyright $\odot 2021$ Institut Agama Islam Negeri Syekh Nurjati Cirebon. All rights reserved.

\section{PENDAHULUAN}

Pangeran Diponegoro adalah tokoh yang monumental karena pertama kali diangkat sebagai pahlawan nasional oleh pemerintah Republik Indonesia dan 
menjadi nama perguruan tinggi serta KODAM di Jawa Tengah. Pangeran Diponegoro menulis sebuah autobiografi yang berjudul Babad Diponegoro. Babad Diponegoro merupakan bagian dari sejarah Jawa yang sudah berlangsung ribuan tahun. Diponegoro adalah tokoh sejarah Jawa abad 19 ketika Pulau Jawa dikuasai Belanda. Diponegoro melawan Belanda sampai akhirnya tertangkap dengan cara licik, yaitu diajak berdamai lalu ditangkap ketika sedang diadakan perundingan. Pangeran Diponegoro lalu dibawa ke Jakarta, kemudian diasingkan ke Menado, Sulawesi Utara, dan terakhir dipindah ke Makassar sampai meninggal pada 8 Januari 1855 (Sahid dkk., 2017).

Di bidang sastra, Pangeran Diponegoro adalah penulis autobiografi pertama dengan karyanya yang berjudul Babad Diponegoro. Karya ini ditulis pada masa pengasingan di Menado pada tahun 1832. Naskah Babad Diponegoro ini sekarang disimpan di Perpustakaan Nasional Jakarta, sebagai koleksi naskah Brandes. Karya ini sudah diakui dunia dengan dimasukkan UNESCO PBB sebagai "memory of the world" pada tahun 2013 (Sudardi, 2012). Babad Diponegoro merupakan babad yang unik karena 3 hal, meliputi: (1) ditulis langsung oleh Pangeran Diponegoro, (3) tentang diri Pangeran Diponegoro, dan (3) ditulis di lokasi yang jauh dari konteks budaya Jawa, yaitu di Manado. Babad ini telah dialihaksarakan oleh PNRI menjadi 4 jilid (Tobroni \& Amilia, 2019).

Sehubungan dengan hal tersebut, babad ini dikaji dari sudut pandang identitas dengan pola pikir sesuai identity theory Sheldon Stryker. Menurut teori ini, terdapat hubungan yang saling mempengaruhi di antara individu dengan struktur sosial yang lebih besar lagi, yaitu masyarakat. Ada hubungan antara konsep peran dengan konsep diri. Teori ini memusatkan perhatiannya pada hubungan saling mempengaruhi di antara individu dengan struktur sosial yang lebih besar lagi, yaitu masyarakat. Individu dan masyarakat dipandang sebagai dua sisi yang tidak terpisahkan. Individu terbentuk karena interaksi. Di pihak lain, struktur sosial membentuk interaksi (Widianti, Nuryatin, \& Indiatmoko, 2017). Seseorang dibentuk oleh interaksi, tetapi struktur sosial membentuk interaksi. Pandangan ini tampaknya setuju dengan perspektif struktural, khususnya teori peran (Gustia, 2017).

Babad Diponegoro dikaji dengan ekspresi identitas antara peran dan diri Diponegoro sebagai orang buangan sekaligus seorang Pangeran dari suku Jawa yang tinggal jauh dari komunitasnya. Penelitian ini mengkaji ekspresi identitas, nilai-nilai budaya yang resisten dalam karya Babad Diponegoro serta unsur-unsur yang berpengaruh dalam komunitasnya di Menado. Hal ini untuk menandaskan juga bahwa sebuah karya tulis tidak dapat lepas dari sosialnya. Karya tulis memiliki model komunikasi tertulis yang menegaskan tentang peran penulis dalam negosiasi dengan pembaca berdasarkan medium teks. Dalam wacana teori interaksi sosial, makna dikatakan sebagai negosiasi konstruk sosial antara penulis dan pembaca dengan medium teks yang secara unik mengkonfigurasi tujuantujuan tertentunya (Nystrand \& Himley, 1984).

Sesuai dengan prinsip di atas, maka pendekatan kajian identitas ini memanfaatkan pendekatan strukturalisme genetik yang mempelajari kelahiran sebuah karya sastra dari aspek asal usulnya. Sastra tidak hanya memberikan hiburan semata, namun juga menyajikan nilai makna kehidupan kepada pembacanya melalui rangkaian peristiwa yang diangkat. Rangkaian alur peristiwa dalam karya sastra tidak hanya bersifat imajinasi atau fiksi, tetapi universal sehingga alur peristiwa sering kali bersifat kompleks. Pengarang dihadapkan pada 
situasi sosial dan situasi pemikirannya. Dapat dikatakan kedua aspek itu menunjukkan bahwa sastrawan membawa ide dari masyarakat. Refleksi hasil dari aspek sosial dalam karya sastra mempengaruhi eksistensi karya itu dalam masyarakat (Sugianto \& Huda, 2017).

Pangeran Diponegoro adalah seorang pangeran yang memiliki rasa identitas yang sangat kuat pada zamannya. Ketika pengaruh Belanda sangat kuat, Pangeran Diponegoro memiliki prinsip identitas yang menyimpang dari Keraton Jawa Mataram. Prinsip itu ialah (1) Pangeran Diponegoro tidak mau diangkat menjadi putra mahkota dan selanjutnya menjadi raja apabila yang mengangkat adalah pemerintah Belanda; (2) Pangeran Diponegoro dalam menyusun barisannya tidak menggunakan sistem pasukan Eropa atau Belanda melainkan menggunakan sistem Kesultanan Turki; (3) dalam menentukan Dalam menentukan ide-ide itu Pangeran Diponegoro mendapatkan inspirasi dari pertapaannya di Parangkusumo. Tindakan ini merupakan suatu usaha untuk mencari identitas dirinya yang diperoleh dari nenek moyang, yaitu Panembahan Senopati yang memperoleh ide untuk mendirikan kerajaan Mataram dengan bersama di Parangkusumo.

Panembahan Senopati melakukan tapa dikarenakan sedang menghadapi konflik dengan ayah angkatnya, Sultan Hadiwijaya. Agar tidak kelihatan menewaskan Sultan Pajang, maka Panembahan Senopati menggunakan kekuatan Ratu Kidul untuk mengalahkan Kesultanan Pajang. Ratu Kidul yang bersedia untuk membantu Panembahan Senopati di dalam menghadapi Sultan Pajang dengan syarat adanya pernikahan dengan Ratu Kidul. Di Parangkusuma terdapat batu hitam (watu gilang) yang dipercaya sebagai tempat pertemuan antara Panembahan Senopati dengan Ratu Kidul. Banyak dari kalangan masyarakat beraliran kejawen meyakini bahwa dengan melakukan ziarah ke petilasan dengan ritual tertentu, maka dengan wasilah tersebut, seseorang akan dapat memperoleh tujuan yang hendak dicapai (Ichsan et al., 2020).

Demikianlah setidaknya tiga unsur identitas lokal yang terdapat dalam diri Pangeran Diponegoro. Hal ini nantinya juga ditemukan dalam Babad Diponegoro. Identitas lokal Pangeran Diponegoro muncul di dalam penulisan babad meskipun babad itu ditulis jauh dari tanah Jawa yaitu di Manado ketika dalam pembuangan pemerintah Belanda. Pangeran Diponegoro membangun identitas dalam menyiapkan perang Jawa selama 12 tahun. Pangeran Diponegoro selama 12 tahun mempersiapkan diri seandainya terjadi perang sabil yang dicita-citakannya .

Tegalrejo merupakan suatu tempat "menjual dan membeli" gagasan, konsep ideologi, politik, kenegaraan, budaya, militer, rencana strategi dan aksi; tempat berkumpulnya pemimpin masyarakat. Hal ini ketika di Kesultanan Yogyakarta terjadi kekosongan kepemimpinan; tempat Diponegoro memperoleh basis legitimasinya melalui permufakatan sukarela dari kelompok yang berkepentingan (Louw, 1894). Sehubungan dengan hal tersebut, penelitian ini berusaha mengkaji aspek identitas yang terdapat dalam Babad Diponegoro.

Penelitian ini pertama-tama mengkaji mengenai ekspresi identitas Pangeran Diponegoro yang tertuang di dalam Babad Diponegoro. Babad tersebut tentu mengandung pesan-pesan yang pernah diberikan kepada pengikutnya. Langkah selanjutnya adalah melihat tentang proses sosial para pengikut Diponegoro yang melarikan diri setelah Pangeran Diponegoro ditangkap oleh Belanda. Salah satu cerita tentang pengikut Pangeran Diponegoro adalah cerita tentang Kyai Zakaria yang melarikan diri ke Gunung Kawi, daerah Malang, Jawa Timur yang akhirnya dimakamkan di daerah itu. Makam tersebut dikenal sebagai Pasarean Gunung 
Kawi. Masyarakat setempat menyebut Kyai Zakaria tersebut sebagai Eyang Panembahan. Orang yang melakukan ritual di Pasarean Gunung Kawi menyatakan diri sebagai cucu Eyang Panembahan melaksanakan selametan atau ritual meminta doa melalui Kanjeng Eyang Penembahan (Nuryani, 2013).

\section{METODE}

Merujuk babad sebagai produk sejarah, maka penelitian ini menggunakan pendekatan deskriptif (Birsyada, 2016). Target penelitian ini ialah mendeskripsikan identitas alamiah, identitas fundamental, dan identitas instrumental dalam Babad Diponegoro dalam kaitan dengan tradisi di Sekitar Pasaeran Gunung Kawi. Penelitian dilakukan mulai 2019 sampai dengan November 2020 yang meliputi penelitian lapangan Pasarean Gunung Kawi dan kajian pustaka dengan homebase di Surakarta.

Objek yang dikaji adalah teks Babad Diponegoro koleksi Brandes nomor 149A, 149B, 149C dan 149D . Metode yang digunakan dalam penelitian ini ialah metode kualitatif dengan kajian pokok pada analisis unsur budaya, khususnya analisis tentang identitas budaya. Aspek ini merupakan kajian pokok dalam metode ini. Lalu dilanjutkan dengan pengkajian resepsi terhadap naskah tersebut dalam Pasarean Gunung Kawi.

Subjek penelitian ini ialah naskah babad Diponegoro yang tersimpan dengan kode koleksi brandes atau BR 149a, b, c, d, dan Tradisi di Pasarean Gunung Kawi. Naskah terdiri atas 4 jilid dan saat ini tersimpan di Perpustakaan Nasional Republik Indonesia. Naskah ini sudah tercatat dalam Katalog induk naskahnaskah Nusantara jilid 4 terbitan Perpustakaan Nasional RI (Badri, 2010). Naskah ini beraksara Jawa dan berbahasa Jawa baru serta berbentuk macapat. Teks Babad Diponegoro merupakan karangan Pangeran Diponegoro sendiri yang ditulis pada tahun 1832 semasa pembuangan di Manado (Dipanegara, 2010). Berikut ini salah satu isi naskah sebagai pengantar yang isinya sebagai berikut.

Sun medar surasaning ati (Saya mengeluarkan suara hati)

Atembang pamiyos (dalam bentuk tembang)

pan kinaryo panglipur (sebagai pengibur)

Aneng kitha Manado duk kardi tan ana kaeksi (Di kota Menado, waktu membuat tidak ada yang melihat),

Nging sihing Hyang Hyang Agung (Hanya kasih Tuhan Yang Agung)

Lara wirang pan wus sun lakoni (sakit malu sudah kujalani)

nging panuwun ingong (hanya saja permintaanku)

Ingkah kari lan kang dingin kabeh (Yang akhir dan yang awal)

kulawarga kang ngestoke yekti (keluarga yang melaksanakan

ing agama nabi (agama Nabi)

oleha pitulung (dapatlah beroleh pertolongan) (Dipanegara, 2010)

Hal yang menjadi pokok kajian ialah tentang identitas lokal dalam Babad Diponegoro. Kajian ini menjadikan babad sebagai sumber informasi karena merupakan satu-satunya sumber yang memiliki deskripsi lengkap tentang Diponegoro. Subjek kajian kedua adalah cerita rakyat tentang pengikut Pangeran Diponegara yang tertuang dalam cerita rakyat tentang berdirinya Pesarean Gunung Kawi. 
Pendekatan yang digunakan dalam penelitian ini ialah pendekatan etnometodologi. Pendekatan ini berupaya untuk memahami, memandang, menjelaskan, dan menggambarkan tata hidup masyarakat. Etnometodologi berusaha memahami cara orang-orang mulai melihat, menerangkan, dan menguraikan keteraturan dunia. Seorang peneliti kualitatif yang menerapkan sudut pandang ini berusaha menginterpretasi kejadian dan peristiwa sosial sesuai dengan sudut pandang objek penelitiannya (Moha \& Sudrajat, 2019).

Langkah penelitian ini menggunakan prosedur analisis data yakni dengan cara mengkategorisasi materi dan melabeli data sehingga dihasilakan makna yang signifikan dengan jelas (Willott \& Larkin, 2012). Prosedur itu dilakukan dengan langkah-langkah: 1) mengkategorisasi dan melabeli Babad Diponegoro dalam hal kaitannya dengan identitas, 2) mengkategorisasi melabeli cerita Pasarean Gunung Kawi, dan 3) mengambil kesimpulan tentang identitas Pangeran Diponegoro dan pengikutnya serta mencari hubungan keduanya.

\section{HASIL DAN PEMBAHASAN}

Apabila diamati dengan saksama, Pangeran Diponegoro memiliki pandangan yang lazim sebagaimana orang Jawa yang masih mahir menggunakan metrum macapat. Pangeran Diponegoro juga percaya pada cerita-cerita legenda dan mitologi seperti cerita Nawangwulan, asal usul Majapahit, cerita para sunan dengan keelokan-keelokan cerita yang luar biasa. Namun, dalam perjuangan Pangeran Diponegoro menggunakan nilai-nilai Islam. Kemungkinan nilai-nilai ini diadopsi dari pemikiran Islam yang berkembang pada saat itu (Musonnif, 2018). Pangeran Diponegoro menuliskan cerita sultan Agung yang mempelajari agama sampai ke Mekkah, Syam, Turki, Mesir dan lain sebagainya dalam naskah Babad Diponegoro.

Selain itu, dalam perjuangannya melawan penjajah Belanda, Pangeran Diponegoro mengadopsi sistem organisasi militer Turki Utsmani. Pinilih, Bulkiya, Nasseran, Harkiya, Burjumuah, Larban, Sipuding, Suratandang, Surapadah,Turkiya, Jayengan, Jagir, Wanangprang, dan Suryagama adalah beberapa nama kesatuan laskar Diponegoro yang diadopsi dari nama-mana kesatuan militer Turki Utsmani. Selain itu, nama-nama pangkat militer seperti seh, setingkat komandan kompi, dulah, setingkat komandan batalion, basah, setingkat komandan brigade, alibasah (ali pasya), setingkat komandan divisi, merupakan hasil adopsi dari militer Turki Utsmani (Musonnif, 2018). Ketika pengasingannya pula Diponegoro menarsasikan tentang Sultan Agung, seorang raja mataram sekaligus nenek moyangnya dalam perjalanan intelektual dan spiritual.

\section{Konflik Internal menjadi Perang Jawa}

Pangeran Diponegoro adalah tokoh sejarah yang sangat terkenal di Indonesia. Pangeran yang berasal dari Kesultanan Yogyakarta ini menunjukkan perjuangan yang gigih dalam melawan VOC Belanda. Bermula dari konflik internal di lingkungan kesultanan Yogyakarta serta konflik dengan VOC Belanda, maka peperangan pangeran Diponegoro melawan Belanda menjadi meluas di Jawa Tengah dan Jawa Timur. Perang tersebut berubah menjadi perang sabil dengan tujuan melawan orang kopar atau kafir. Dalam penyebutan, pasukan musuh disebut sebagai orang kafir. Kadang-kadang juga menyebut sebagai Welanda atau Belanda. Hal tersebut dapat ditemukan pada kutipan tembang Mas Kumambang berikut. 
Campuhing prang kapir kathah ingkang mati

Kapitannya pejah

Kelawan litnanireki

Kang kathah lumajeng samya

\section{Lajeng katur kang sirah mring Sri Bupati \\ Malih kang winarna \\ Tumenggeng Mondhaling neki \\ Sakit tinulup Welanda Diponegoro III, 50)}

(Dalam peperangan melawan orang kafir, banyak yang mati banyak yang mati. Kapiten dan Letnan nya juga, tetapi yang banyak melarikan diri.

Kepala lalu dihaturkan kepada sri bupati (Pangeran Diponegoro), cerita selanjutnya bahwa Tumenggung Mandala sakit terkena tulup oleh Belanda)

Uraian di atas menunjukkan bahwa Pangeran Diponegoro menyebut pasukan Belanda sebagai pasukan kafir. Sementara yang tewas dalam peperangan tersebut disebut sebagai sabil. Artinya, orang yang meninggal dunia dalam perjuangan di jalan Allah.

Konflik internal keraton telah berkembang menjadi perang agama. Hal ini sebenarnya bermula dari ketersinggungan Pangeran Diponegoro terhadap sikap Belanda dan Patih Danurejo. Salah satu peristiwa yang menjadikan Pangeran Diponegoro tersinggung adalah perjanjian lisan pada tanggal 1 Januari 1825 ketika kasunanan Surakarta dan kesultanan Yogyakarta mengadakan perjanjian dengan residen Belanda. Dalam perjanjian itu, Sultan Yogyakarta yang masih anak-anak diwakili oleh Patih Jogjakarta. Sebagai wali Sultan, pangeran Diponegoro merasa tersinggung dengan peristiwa ini karena seharusnya dialah yang mewakili Sultan untuk mengadakan perjanjian dengan Belanda tersebut. Pangeran Diponegoro bersama Pangeran Mangkubumi kemudian menolak perjanjian tersebut. Pangeran Diponegoro berpendapat bahwa para wali sultan-lah yang berhak mewakili Sultan dan bukan Patih Danurejo. Penolakan tersebut dianggap oleh Belanda sebagai pemberontakan dari sinilah mulai terjadinya konflik antara Belanda dengan Pangeran Diponegoro dan para pendukung (Djamhari, 2014).

\section{Tradisi Babad tentang Diponegoro}

Kisah tentang Pangeran Diponegoro ini lalu memasuki tradisi tulis dalam bentuk Babad Tanah Jawi karangan Pangeran Diponegoro yang kemudian disebut sebagai Babad Diponegoro. Sebagaimana sebuah babad, maka bagian awal Babad Diponegoro menceritakan tentang asal-usul leluhur Pangeran Diponegoro. Dimulai dari Prabu Brawijaya di Majapahit akhir serta munculnya para wali dan menyebarnya agama Islam di Pulau Jawa, seperti: Sunan Bonang, Sunan Makdum, Sunan Kalijaga (Syekh Malaya), Sunan Gunung Jati, Ki Agung Tarub yang dikenal dengan Jaka Tarub. Ada percampuran juga tradisi Islam, Hindu, dan Budha. Dalam budaya Jawa dikenal ajaran kejawen Sunan Kalijaga yang merupakan percampuran antara tradisi Islam dan Jawa, serta Hindu dan Budha (Subqi et al., n.d.). Ajaran ini tampaknya juga memengaruhi babad ini. Diponegoro memang masih menganut paham kejawen yang ditunjukan dengan laku tirakat seperti Panembahan Senopati dan tergambar dalam Serat Wedhatama. 
Dalam ajaran ini orang harus menjalankan laku untuk mengendalikan dari hawa nafsu dengan cara mencegah "dhahar lawan guling" atau yang sering disebut mati raga atau "mengendalikan angkara murka, selalu bersyukur kepada Tuhan dan mendekat kepada Tuhan (Sarsito, 2011).

Pangeran Diponegoro kiranya juga memahami karya-karya tradisional dalam wayang dan mengidolakan Arjuna sebagai pahlawan perang yang sakti dan suka bertapa. Kami melihat Pangeran Diponegoro ini masih kelihatan mengambil perilaku seperti Arjuna ketika melakukan tapa brata sehingga dapat mengalahkan musuh-musuhnya dan dikasihi para Dewa. Pangeran Diponegroro mungkin mengidentifikasi diri sebagaimana gambaran Arjuna oleh Empu Kanwa dalam Arjunawiwaha. Mpu Kanwa telah menghadirkan Arjuna sebagai seorang yogi, yang telah berhasil dalam tapanya. Arjuna adalah orang yang memiliki kelanggengan pikiran dalam memuja Śiwa, sesuatu yang menjadi sebab mendapat anugerah Hyang Śiwa. Arjuna memang seorang yogi yang paham betul makna pasu, pati dan pasa. Pasu tiada lain adalah manusia sendiri, pati adalah Hyang Siwa, sedangkan pasa adalah dunia maya yang mengikat manusia. Seorang yogi dapat membebaskan dirinya dari godaan dan ikatan pasa itu sendiri, hanya dengan demikian ia dapat bersatu dengan Hyang Śiwa (Windya, 2019). Identitas Pangeran Diponegoro sebagai orang Jawa mengikuti gambaran Arjuna ini, tetapi dalam prinsip hidup tetap berpegang pada agama Islam. Dalam Babad Diponegoro digambarkan bahwa Pangeran Diponegoro selalu dekat dengan Tuhan bagaikan yogi tidak perjuangannya tidak mengenal rasa takut.

Secara prinsip, Babab Diponegoro tidak jauh berbeda dengan Babad Tanah Jawi lainnya. Ciri cerita babad adalah berkaitan dengan cerita keraton seperti keraton Pajajaran, Majapahit, Demak, Pajangan, Mataram, dan Kartasura. Kadangkala cerita dimulai dari cerita Nabi Adam dan berlanjut sampai dengan masa Kartasura tahun 1745 sehingga dapat diduga bahwa babad muncul pada sekitar akhir abad 17 sampai dengan awal abad ke 18. Babad kemungkinan dipengaruhi cerita wayang yang disebut kandha. Isi kandha adalah ringkasasn cerita wayang dan itu membentuk sejarah palsu (psedohistory) yang dipercaya terjadi di Jawa pada masa lalu (Ras, 1987).

Fakta sejarah menunjukkan bahwa kondisi ekspresi psikis para pujangga memengaruhi beberapa versi penulisan Babad Tanah Jawi. Ngawula pada raja atau gustinya merupakan kewajiban para pujangga menurut pandangan keluarga keraton. Mengabdi pada raja memiliki arti mengabdi kepada Tuhan, hal tersebut sesuai dengan ideologi atau pandangan masyarakat Jawa bahwa di muka bumi ini raja adalah jelmaan Tuhan (pusat mikrokosmos). Maka dalam perspektif critical pedagogy sastra, Babad Tanah Jawi yang dibuat oleh pujangga istana adalah bentuk legitimasi serta dominasi kekuasaan raja. Dalam Babad Tanah Jawi, pemaparan budaya keraton dengan genealogi keluarga keraton yang penuh dengan kesakralan, cerita mitologi, dan magis menunjukkan sisi dominasi. Oleh karena itu, pengetahuan yang terdapat dalam Babad Tanah Jawi merupakan representasi dari legitimasi kekuasaan dan budaya keraton. Babad Tanah Jawi juga menunjukkan upaya pengembalian sistem kelas atau kasta sebelum adanya agama Islam dan imperiumisasi budaya (Bisyarda, 2016).

Babad Diponegoro masih tentang keraton, khususnya dimulai keraton Demak. Babad ini sudah meninggalkan cerita tentang Majapahit, Pajajaran, dan cerita pewayangan. Namun dalam interpretasi beberapa peristiwa, tampak bahwa identitas diri Pangeran Diponegoro dimunculkan dengan mengubah beberapa 
bagian untuk menunjukkan superioritas orang Jawa sekaligus superioritas Pangeran Diponegoro. Bagian utama Babad Diponegoro adalah cerita tentang kehidupan Pangeran Diponegoro, khususnya dalam peperangan menghadapi Belanda. Terdapat juga kejadian pada saat Pangeran Diponegoro dan sekelompok pendukungnya merasa sakit hati atas perlakuan Belanda terhadap kesultanan Yogyakarta. Demikian juga dengan ketersinggungan lain, yakni ketika Belanda meninggalkan Pangeran Diponegoro begitu saja.

Konflik-konflik Belanda dan Pangeran Diponegoro meledak dengan adanya peristiwa pasang pathok atau pemasangan tiang pancang untuk membangun jalan. Belanda memerintahkan Patih Danurejo yang pro-Belanda untuk memasang tiang pancang sebagai tanda pembuatan jalan dan batas itu melintasi rumah Pangeran Diponegoro di Tegalrejo. Hal ini ini menjadi suatu berita yang sangat besar dan Pangeran Diponegoro serta para pengikutnya mengganti tiang pancang itu dengan tombak-tombak sebagai tanda perlawanan (Maulana, 2015).

Tersiarlah kabar bahwa Pangeran Diponegoro akan ditangkap oleh Belanda. Para pendukung Pangeran Diponegoro kemudian berkumpul di rumah Pangeran Diponegoro untuk menjaga Pangeran Diponegoro dari serangan Belanda tersebut. Terkumpullah 1500 orang yang siap untuk membela Pangeran Diponegoro bila sewaktu-waktu ditangkap oleh Belanda. Karena peristiwa makin genting, maka Residence Yogyakarta memanggil Pangeran Diponegoro untuk datang ke Loji atau benteng Belanda.

Atas saran Pangeran Mangkubumi, undangan itu ditolak oleh Pangeran Diponegoro karena Pangeran Mangkubumi khawatir bahwa Pangeran Diponegoro ditangkap di tempat itu. Akhirnya, presiden mengirimkan pasukan untuk menangkap Pangeran Diponegoro ke Tegalrejo. Terjadilah suatu peperangan yang seru dan rumah Pangeran Diponegoro di Tegalrejo berhasil dibakar sementara Pangeran Diponegoro dan pasukannya kemudian melarikan diri ke Selarong (Djamhari, 2014). Inilah permulaan awal Perang Diponegoro yang sangat terkenal dan menguras keuangan pemerintah Belanda itu. Peperangan melawan Belanda yang dipimpin oleh Pangeran Diponegoro ini kemudian meluas di Jawa Tengah dan Jawa Timur.

Tampaknya Perang Diponegoro ini sudah dipersiapkan dengan baik sejak awal mula sebagai bentuk kekecewaan Pangeran Diponegoro dan para pengikutnya terhadap Belanda dan dan kesultanan. Setidaknya, selama 12 tahun, Pangeran Diponegoro telah melakukan persiapan untuk melakukan pemberontakan dengan pembuatan pabrik mesiu di desa Geger, Yogyakarta, Parakan, Gunung Kidul, dan Kembangarum. Pada pertengahan tahun 1825, prajurit Pangeran Diponegoro telah menyiapkan logistik dengan membeli padi secara besar-besaran (Djamhari, 2014).

Kisah Pangeran Diponegoro ini kemudian menjadi legenda rakyat sehingga tersebar di masyarakat karena memang jangkauan perang ini meliputi wilayah dari Pasuruan sampai dengan Tegal. Banyak tokoh atau pesantren dari rentang wilayah tersebut yang ikut terlibat. Perang Diponegoro memiliki ciri sebagai perang rakyat dengan berlandaskan kepada nilai-nilai jangan Islam dengan cita-cita menemukan Ratu Adil yang menguasai Pulau Jawa. Konsep Ratu Adil ini masuk sejak diterima ajaran Islam, namun konsep itu juga dilandaskan pada konsep-konsep Jawa yang dikembangkan oleh Sunan Kalijaga dengan istilah "adil paramarta" yang mengaplikasi konsep adil dengan ketokohan Yudhistira (Supadjar, 1994). 
Perjuangan Pangeran Diponegoro yang pada awalnya berhasil menguasai wilayah Yogyakarta, makin lama makin surut dengan tertangkapnya atau gugurnya para prajurit pilihan yang sangat berperan dalam perjuangan itu. Akhirnya pada 28 Maret 1830, Pangeran Diponegoro menyetujui suatu perjanjian di Magelang dan ditangkap dalam perjanjian tersebut. Dengan penangkapan Pangeran Diponegoro dengan cara licik ini, maka berakhirlah peperangan tersebut. Dari sini kemudian berlanjutlah suatu tradisi baru berupa tradisi lisan.

\section{Tradisi Lisan Pangeran Diponegara}

Cerita tentang Pangeran Diponegoro yang kemudian dilanjutkan oleh para pengikutnya termasuk dalam golongan folklor. Hal ini sesuai dengan ciri-ciri folklore, berupa: 1) disebarkan secara lisan, dari mulut ke mulut dari generasi ke generasi berikutnya, 2) tradisional, disebarkan dalam jangka waktu yang lama. Paling sedikit 2 generasi, 3) anonim, atau yang artinya nama sang pencipta folklor tidak diketahui lagi, 4) berfungsi sebagai alat pendidik dan protes sosial, 5) bersifat pralogis, yaitu mempunyai logika sendiri yang berbeda dengan logika pada umumnya, 6) milik bersama, dan 7) terlihat polos dan lugu, sehingga terkesan kasar dan spontan, itu karena agar mudah dipahami dan diingat (Fitrianita et al., 2018).

Tradisi lisan mengisahkan bahwa Diponegoro memang telah tertangkap dan diasingkan ke luar pulau Jawa. Selanjutnya, muncullah cerita baru tentang pasukan Diponegoro yang terpisah-pisah satu sama lainnya dan menuju ke berbagai tempat. Salah satu cerita ialah tentang Kyai Zakaria atau yang sering disebut sebagai Eyang Joego yang melarikan diri ke Jawa Timur. Inilah yang kemudian melahirkan folklor tentang Pesarean Gunung Kawi yang di dalamnya dimakamkan Kyai Zakaria dan pengikutnya. Pesarean Gunung Kawi terkenal sebagai tempat untuk mencari penglarisan dengan memohon berkah kepada yang dimakamkan di tempat tersebut.

Mayoritas masyarakat yang berada di sekitar gunung Kawi maupun peziarah, mereka berkeyakinan dan beranggapan bahwa Gunung Kawi memiliki aura gaib dan hal di luar logika manusia atau dapat dikatakan mistis bagi pencari pesugihan atau tujuan lainnya. Hal tersebut karena adanya ritual kejawen yang dilakukan dalam aktivitas ziarah yaitu mengelilingi pasarehan dengan jumlah ganjil dengan sugesti akan lebih afdhol ketika dilakukan di atas pukul 12 malam. Selanjutnya duduk di pohon dewa Ndaru, nyekar, mandi di air sumber dan melakukan syukuran selametan. Ritual-ritual tersebut paling banyak dilakukan pada malam Jumat legi, Senin pahing, Malam syuro, dan Tahun baru (Harianto, 2017).

Pasarean Gunung Kawi terletak di wilayah administrasi Desa Wonosari, Kecamatan Wonosari Kabupaten Malang, Jawa Timur. Sebagai sebuah ruang ritual, keberadaan Pasarean Gunung Kawi disakralkan. Para peziarah yang ingin datang ke wilayah ini berasal dari berbagai tempat. Bahkan terkenal sampai mancanegara. Setiap hari, kawasan Pasarean Gunung Kawi banyak didatangi oleh pengunjung yang bertujuan untuk berziarah ke makam Eyang Djoego dan R.M. Iman Soedjono atau hanya sekadar berwisata.

Keberadaan pasarean Gunung Kawi sebagai ruang ritual telah dikenal oleh masyarakat sejak lama. Ketenaran nama pasarean Gunung Kawi disebabkan oleh dua hal, yaitu 1) tokoh yang dimakamkan merupakan tokoh historis yang ikut menjadi pengikut Pangeran Diponegoro melawan Belanda dan 2) tumbuhnya kepercayaan masyarakat terhadap makam kedua tokoh sebagai media perantara 
pengabul hajat. Hal ini menjadikan nama pasarean Gunung Kawi semakin menggaung.

Pasarean Gunung Kawi dikenal oleh masyarakat luas. Pengunjung yang datang ke tempat ini tidak hanya berasal dari masyarakat lokal di sekitar Kabupaten Malang, tetapi dari luar Pulau Jawa hingga mancanegara. Para pengunjung pasarean Gunung Kawi, di antaranya dari Singapura, Belanda, Malaysia, dan Inggris. Pasarean Gunung Kawi merupakan sebuah area yang cukup luas dengan makam kedua tokoh yang disemayamkan. Terdapat beberapa bangunan berjajar di kompleks bangunan Pasarean Gunung Kawi, mulai bangunan peribadatan, tempat pertunjukan budaya, lapak pedagang, penginapan, bangunan bersejarah, serta area makam Eyang Djoego dan R.M. Iman Soedjono.

Dari area parkir, pengunjung harus menaiki anak tangga yang mengarah pada puncak tempat makam berada. Sepanjang jalan dari pelataran parkiran hingga makam, berjajar lapak pedagang yang menjajakan beraneka ragam kebutuhan pengunjung, seperti makanan, oleh-oleh, jimat, penginapan, hingga keperluan sarana ritual pengunjung. Selain itu, di kompleks Pasarean Gunung Kawi juga banyak ditemui para pengemis musiman yang biasanya berada di sekitar kompleks Masjid Agung R.M. Iman Soedjono untuk mengharapkan pundipundi rupiah dari belas kasihan pengunjung.

Sebagai ruang ritual, suasana kesakralan tidak tampak di Pasarean Gunung Kawi. Hal yang lebih tampak adalah corak keragaman agama dan budaya yang berasal dari berbagai penganut kepercayaan dan etnis. Para pengunjung yang datang dapat melihat arsitektur bangunan-bangunan yang bercirikan Tionghoa dan Jawa. Selain itu juga berdiri bangunan-bangunan peribadatan bagi pemeluk agama Islam, Kristen, Hindu, Budha, dan Konghucu. Suasana bangunan-bangunan yang mencirikan kebudayaan Indonesia justru lebih terasa ketika pengunjung datang ke kawasan ini. Meskipun begitu, nuansa sakral yang ada di Pasarean Gunung Kawi tidak sepenuhnya hilang. Pengunjung yang datang dapat mencium aroma dupa, kemenyan, dan bunga-bunga. Aroma ini terutama di kawasan sekitar makam Eyang Djoego dan R.M. Iman Soedjono.

\section{Kontradiksi Pandangan Pangeran Diponegoro dan Pesarean Gunung Kawi}

Babad Diponegoro memiliki pandangan tersendiri tentang hubungan antara Mataram dan kompeni atau VOC. Dalam Babad Diponegoro jilid 2 halaman 6 disebutkan bahwa serangan Mataram ke Jakarta atau Betawi dimenangkan oleh pasukan Mataram. Pasukan Mataram hanya meminta agar pasukan VOC atau Gubernur Jenderal memberikan upeti kepada pasukan Mataram. Hal ini merupakan perjanjian antara Tumenggung Wiraguna yang didampingi oleh juru tulis bernama Jiwaraga sebagai wakil dari Mataram dalam menghadapi gubernur jenderal dari Batavia.

Kehidupan Pangeran Diponegoro memang unik. Pangeran Diponegoro menolak untuk aktif berpolitik di dalam Kesultanan Jogjakarta. Pangeran Diponegoro tidak ingin jabatan dan sengaja menolak saat diangkat menjadi pangeran Adipati atau putra mahkota. Pangeran Diponegoro memilih tinggal di Tegalrejo yang merupakan tanah warisan dari nenek moyangnya. Dari Tegalrejo inilah, perang Diponegoro kemudian membangun jaringan keagamaan dengan tokoh-tokoh yang ada di Jawa. Masa muda Pangeran Diponegoro diisi dengan berguru ke berbagai pesantren di Jawa. Kebiasaan tersebut membuatnya memiliki hubungan yang luas dengan tokoh-tokoh Islam dan pesantren-pesantren di Jawa. Hal ini yang membuat Pangeran Diponegoro tidak tertarik dengan kehidupan 
dalam Kesultanan Yogyakarta. Diponegoro lebih suka membangun cita-cita untuk mendirikan negara Islam.

Meskipun sudah memeluk Islam, dari segi ideologi Diponegoro masih mengikuti ideologi Jawa tentang penokohan Arjuna. Pada umumnya orang Jawa mengagumi tokoh Arjuna yang memiliki akar pada cerita Kakawin Arjunawiwaha dari tradisi Jawa Kuna dan tergambar dalam wayang Jawa. Diponegoro tampaknya mengidentifikasi diri juga sebagai Arjuna yang menguasai tanah Jawa. Sesuatu yang tidak tampak lagi ialah kepercayaan pada Dewa Siwa yang memberi anugerah berupa panah pasopati atau anugerah lain. Peran Dewa Siwa sudah digantikan dengan peran Allah sesuai tuntunan ajaran agama Islam (Windya, 2019).

Pangeran Diponegoro hidup dengan mencontoh kehidupan Nabi Muhammad yang sederhana. Hal ini pulalah yang menjadikan Pangeran Diponegoro tidak memakai pakaian kebesaran Jawa, tetapi lebih senang memakai jubah putih. Diponegoro juga mengubah namanya menjadi Abdul Hamid atau Ngabdulkamid yang artinya hamba dari yang patut dipuji. Diponegoro juga berpandangan bahwa Jawa pada masa lalu, khususnya di masa pemerintahan ayahnya, dipandang sebagai zaman Jahiliyah yang mirip dengan konsep Islam sebelum kedatangan Nabi Muhammad Saw.

Namun hal terebut bila dibandingkan dengan Eyang Joego atau Kyai Zakaria ternyata bertolak belakang. Dalam narasi cerita lisan memang disebutkan bahwa Kyai Zakaria dan pengikutnya adalah guru spiritual Pangeran Diponegoro. Di dalam Kompleks makam tersebut, juga ditemukan masjid kuno. Namun, yang terjadi pada saat ini, banyak orang keliru dalam memandang Kyai Zakaria tersebut. Kyai Zakaria yang sudah meninggal makamnya dikunjungi dalam rangka untuk mendapatkan kemajuan duniawi.

Tabel 1.

\section{Gambaran Kontradiksi Pangeran Diponegoro dan Pasarean Gunung Kawi}

\begin{tabular}{|c|c|c|}
\hline No. & Pangeran Diponegoro & Pasarean Gunung Kawi \\
\hline 1 & Tokoh muslim & $\begin{array}{l}\text { Menjadi ritual kejawen dari } \\
\text { berbagai kepercayaan }\end{array}$ \\
\hline 2 & Berjuang mendirikan negara Islam & $\begin{array}{l}\text { Tempat mencari penglarisan, bebas } \\
\text { dari politik }\end{array}$ \\
\hline 3 & $\begin{array}{l}\text { Berjuang bukan untuk urusan } \\
\text { duniawi }\end{array}$ & $\begin{array}{l}\text { Berjuang untuk urusan duniawi dan } \\
\text { untuk pribadi }\end{array}$ \\
\hline 4 & $\begin{array}{l}\text { Islam dijadikan simbol utama } \\
\text { perjuangan }\end{array}$ & $\begin{array}{l}\text { Islam dijadikan sebagai pelengkap, } \\
\text { ritual yang utama justru } \\
\text { bertentangan dengan Islam }\end{array}$ \\
\hline
\end{tabular}

Seiring dengan perkembangan pergaulan dengan masyarakat Cina, maka di lokasi Pasarean Gunung Kawi juga muncul klenteng tempat ibadah orang Cina. Kemunculan tempat ibadah Khonghucu atau Tridarma ini bermula dari adanya orang Cina yang mengabdikan diri di makam Eyang Joego. Orang ini merasa hidupnya berhasil berkat pengabdiannya di makam tersebut. Sebagai bentuk penghargaan dan ucapan terima kasih, orang tersebut membangun klenteng khas masyarakat Tionghoa. 
Gunung Kawi memiliki teritori dan dalam ritual ada beberapa wilayah seperti untuk agama Islam, kejawen, dan tridarma (China) sehingga dapat menampung berbagai kelompok masyarakat (Ayu, Antariksa, \& Ridjal, 2014). Cerita itu bermula pada tahun 1931, seorang Tionghoa bernama Tan Kie Yam merupakan orang Tionghoa pertama yang datang berziarah ke Gunung Kawi. Pak Yam merasa tenang hidup di sana dan memutuskan untuk menetap di Wonosari untuk mengabdi kepada Eyang Djoego dan R.M. Iman Soedjono. Selain itu, Tjia Tjian Tjin juga ingin menjadi cantrik dengan membersihkan dan memperbaiki makam. Tjia Tjian Tjin ingin unjuk bakti karena anaknya yang celaka dan tidak bisa jalan telah disembuhkan oleh Eyang Djoego. Demikian pula dengan Kwee Yan Hoo juga membaktikan dirinya bekerja apa saja di Gunung Kawi karena sebagai rasa terima kasih karena sakit sesak nafasnya telah disembuhkan oleh Eyang Djoego (Sulistyorini, et al., 2019).

Tan Kie Yam memperhatikan akses jalan ke Gunung Kawi. Ia membaktikan dirinya untuk kepentingan orang banyak dengan cara membangun jalan dari pasarean hingga ke dekat terminal atau stamplat. Tan Kie Yam meninggal pada tahun 1964. Keberadaan Pak Yam di Wonosari ini mendorong etnis Tionghoa lain untuk berkunjung ke Gunung Kawi. Ada juga Ong Hok Liong atau Pak Samsi yang masih saudara dengan Tan Kie Yam. Ong Hok Liong dikenal sebagai pengusaha rokok Bentoel. Ketika ia dan istrinya menjenguk Tan Kie Yam, bertemu dengan Mbah Djuwul. Mbah Djuwul merupakan istri R.M. Iman Soedjono. Setelah suaminya meninggal, Mbah Djuwul menjadi juru kunci di Pasarean. Oleh Mbah Djuwul, Tan Kie Yam diberi dua biji bentul, yaitu tanaman gunung sejenis talas. Terinspirasi dari hal tersebut, Ong Hok Liong mencoba membuat rokok dengan cap Bentoel. Akhirnya, usahanya berhasil sampai dengan sekarang. Berita keberhasilan usaha Ong Hok Liong ini tersebar sampai ke manamana. Hal inilah yang kemudian banyak etnis Tionghoa ingin berkunjung ke Gunung Kawi (Badri, 2010).

\section{SIMPULAN}

Berdasarkan uraian di atas dapat disimpulkan bahwa Babad Diponegoro mengekspresikan ide dan cita-cita Pangeran Diponegoro dengan identitas Islam. Eyang Joego atau Kyai Zakaria dan R. M. Sujono merupakan simbol identitas Islam di Gunung Kawi. Namun, ternyata identitas keislaman tersebut luntur dan berubah menjadi identitas kejawen. Hal tersebut semakin tidak jelas ketika muncul tradisi dari Tionghoa dalam tradisi narasi di Gunung Kawi. Nilai-nilai dalam menegakan Islam berubah menjadi nilai-nilai untuk mencapai kesuksesan duniawi. Pengaruh paham materialisme telah masuk ke dalam tata kehidupan masyarakat di Gunung Kawi dan penilaian kesuksesan dinilai dari kesuksesan duniawi.

\section{UCAPAN TERIMA KASIH}

Terima kasih kepada P2M Dikti yang telah membiayai riset ini pada tahun Anggaran 2020 berdasarkan Amandemen Kontrak Penelitian Tahun Anggaran 2020 antara Direktorat Riset dan Pengabdian Masyarakat Deputi Bidang Penguatan Riset dan Pengembangan, Kementerian Riset dan Teknologi/BRIN dengan Universitas Sebelas Maret Nomor 166/SP2H/AMD/LT/DRPM/2020. 


\section{DAFTAR PUSTAKA}

Ayu, D., Antariksa, \& Ridjal, A. M. (2014). Fleksibilitas Teritori Ruang Ritual pada Pesarean Gunung Kawi Kabupaten Malang. Arsitektur E-Journal, 7(1), 20-28.

Badri, A. (2010). Percampuran budaya Islam, Jawa, dan Cina dalam membangun kolaborasi sosial pada masyarakat daerah gunung kawi kabupaten Malang (Doctoral dissertation, Universitas Negeri Malang).

Bisyarda, M. I. (2016). Budaya Keraton Pada Babad Tanah Jawi Dalam Perspektif Pedagogi Kritis. Sejarah Dan Budaya: Jurnal Sejarah, Budaya, Dan Pengajarannya, 10(2), 174-185. https://doi.org/10.17977/um020v10i22016p174

Dipanegara, P. (2010). Babad Diponegara (N. Noegraha (ed.); Alih Aksar). Perpuatakaan Nasional Republik Indonesia.

Djamhari, S. A. (2014). Strategi Menjinakkan Diponegoro: Stelsel Benteng 18271830. Komuniasi Bambu.

Fitrianita, E., Widyasari, F., \& Pratiwi, W. I. (2018). Membangun Etos dan Kearifan Lokal melalui Folklor: Studi Kasus Folklor di Tembalang Semarang. Endogami: Jurnal Ilmiah Kajian Antropologi, 2(1), 71-79. https://doi.org/10.14710/endogami.2.1.71-79

Gustia, B. (2017). Visual Content Analysis atas Penggambaran Elit Bisnis dalam Laporan Tahunan (Studi Kasus pada Laporan Tahunan PT. Telkom Indonesia Tbk. Tahun 2013-2015). 979-992. https://lens.org/145-667-280977-901

Harianto, B. (2017). Potret Keberagaman dan Kearifan Lokal di Gunung Kawi. Thaqayiyyat, 18(2), 172-185.

Ichsan, Y., Hanafiah, Y., Dahlan, U. A., \& Dahlan, U. A. (2020). Mistisisme Dan Transendensi Sosio-Kultural Islam di Pesisir Pantai Parangkusumo Yogyakarta. Fikri: Jurnal Kajian Agama, Sosial dan Budaya i. 5(1). 21-26. https://doi.org/10.25217/jf.v5i1.856

Louw, P. J. (1894). De Java Oorlog van. 1825-1830. E.J.Brill.

Maulana, D. (2015). Peran Jaka Tingkir dalam Merintis Kerajaan Pajang 15461586 M. 22-39.

Moha, I., \& sudrajat, D. (2019). Resume Ragam Penelitian Kualitatif. https://doi.org/10.31227/osf.io/wtncz

Musonnif, A. (2018). Relasi Intelektual, Jawa Islam, Bugis Islam, dan Turki Utsmani (Tinjauan Atas Sistem Kalender dalam Serat Widya Pradana, Lontara Pananrang dan Ruzname Darendeli). Kontemplasi, 6(1), 63-78. https://doi.org/10.21274/kontem.2018.6.1.63-78

Nuryani, N. (2013). Struktur Wacana Ritual (Studi Kasus Ritual Selametan di Pesarean Gunung Kawi, Malang, Jawa Timur). Adabiyyāt: Jurnal Bahasa Dan Sastra, 12(1), 1-24. https://doi.org/10.14421/ajbs.2013.12101

Nystrand, M., \& Himley, M. (1984). Written Text as Social Interaction. Theory Into Practice, 23(3), 198-207. https://doi.org/10.1080/00405848409543114

Ras, J. J. (1987). The Genesis of The Babad Tanah Jawi; Origin and Function of The Javanese Court Chronicle. Bijdragen Tot de Taal-, Land- En Volkenkunde / Journal of the Humanities and Social Sciences of Southeast Asia, 143(2), 343-356. https://doi.org/10.1163/22134379-90003331

Sahid, N., Susantina, S., \& Septiawan, N. (2017). Symbolic Meaning of Drama "Perlawanan Diponegoro." Harmonia: Journal of Arts Research and 
Education, 16(2), 153-162. https://doi.org/10.15294/harmonia.v16i2.7445

Sarsito, T. (2011). Javanese Culture as Guidance for Suharto's Personal Life and for His Rule of the Country. Southeast Asian Journal of Social and Political Issues - Vol. 1, No. 1, March 2011 - 2, 1(1), 2-23.

Subqi, I., Sutrisno, \& Ahmadiansah, R. (2018). Islam dan Budaya Jawa. Kartosuro: Penerbit Taujih.

Sudardi, B. (2012). The Javanese War: Prince Diponegoro and the Legendary Rebellion Movement against the Dutch Colonial Regime, 3170-3178.

Sugianto, I., \& Huda, N. (2017). Strukturalisme Genetik dalam Cerpen Slum Karya Hanif Nashrullah. Fonema: Jurnal Edukasi Bahasa dan Sastra Indonesia, $\quad 4(1) . \quad 48-58$. https://ejournal.unitomo.ac.id/index.php/pbs/article/view/413/263

Sulistyorini, D., Sudardi, B., Warto, W., \& Wijaya, M. (2019). Culture Tourism to Pesarean Kawi Mountain as A Culture of Cultural Products. 279 (Icalc 2018), 175-180. https://doi.org/10.2991/icalc-18.2019.25

Supadjar, D. (1994). Konsep Keadilan Sosial di Balik Mitos Ratu Adil. Jurnal Filsafat, Seri 19. 1-5.

Tobroni, F., \& Amilia, F. (2019). Agama dan Hak Milik Sebagai Spirit Perlawanan Rakyat Semesta dalam Perang Diponegoro. Media Komunikasi Sosial Keagamaan, 19(2), 326-348.

Widianti, N., Nuryatin, A., \& Indiatmoko, B. (2017). Nilai Moral dalam Cerita Babad Cirebon: Berdasarkan Penceritaan di Keraton Kanoman. Indonesian Language Education and Literature, 3(1), 24-31.

Willott, S., \& Larkin, M. (2012). Introduction to the Special Issue on Qualitative Research and Clinical Psychology. Qualitative Research in Psychology. 9(1), 1-4. https://doi.org/10.1080/14780887.2012.630622

Windya, I. M. (2019). Kakawin Arjuna Wiwāha: Kajian Teologi Hindu. Genta Hredaya, 03(02), 58-67. 